\title{
Molecular evidence for relapse of an imported Plasmodium ovale wallikeri infection
}

\author{
Luzia Veletzky ${ }^{1,2}$, Mirjam Groger ${ }^{1}$, Heimo Lagler ${ }^{1}$, Julia Walochnik ${ }^{3}$, Herbert Auer ${ }^{3}$, Hans-Peter Fuehrer ${ }^{4}$ \\ and Michael Ramharter $2,5^{*}$ (D)
}

\begin{abstract}
Background: Malaria caused by Plasmodium ovale spp. has been neglected by and large from research and has received only little scientific attention during the past decades. Ovale malaria is considered to feature relapses by liver hypnozoites although scientific evidence for this paradigm is scarce.

Case presentation: Here, the case of a 16-year-old male, who presented with fevers to the outpatient department in Vienna, Austria, after travelling to Uganda and Papua New Guinea is described. Infection with Plasmodium malariae was diagnosed by microscopy and the patient was treated accordingly with a full course of supervised artemetherlumefantrine. He was discharged in good clinical condition with a negative blood smear. One month after initial diagnosis, he returned complaining of fever. Thick blood smear was positive again for malaria parasites, which were confirmed as P. ovale wallikeri by PCR. Retrospective analysis revealed the identical Plasmodium spp. in the initial blood samples. Molecular analysis of various gene loci (nuclear porbp2, 18S rRNA and potra genes) gave identical results providing further evidence for relapse by an identical parasite genotype. Consecutively, the patient was retreated with artemether-lumefantrine and received a regimen of primaquine according to WHO guidelines.
\end{abstract}

Conclusion: Conclusive evidence for relapses with P. ovale spp. is rare. The presented case provides convincing confirmation for the relapse paradigm based on re-appearing parasitaemia following supervised treatment in a nonendemic region with a parasite strain of identical genotype.

Keywords: Malaria, Plasmodium ovale, Plasmodium ovale wallikeri, Relapse, Case report

\section{Background}

Plasmodium ovale malaria has been neglected largely from research in the past decades with the primary focus being laid on falciparum and to a lesser extent vivax malaria. Even though evidence is scarce, $P$. ovale is considered a relapsing Plasmodium spp. by analogy to Plasmodium vivax for which evidence for liver hypnozoites is well-established [1].

In general, a recurrence of parasites after initial treatment can be due to recrudescence of a not completely cleared bloodstream infection, to a new infection or to a relapse originating from dormant liver stages. The existence of $P$. ovale hypnozoites was, however, never firmly established nor has a clinical trial on the nature of such relapses been performed [2]. Most of the information available on $P$. ovale relapses has derived from observations from malaria infection therapy for neurosyphilis in the first half of the 20th century or from case reports. Further evidence making use of molecular methods is largely missing. Astonishingly, as recently described by a systematic review, from the first description of the species in 1922 until 2015 less than 20 case reports have been published on potential relapses of $P$. ovale spp. [2]. Further evidence proving or refuting the relapse paradigm for $P$. ovale is, therefore, warranted not least to provide evidence for current guidelines for anti-hypnozoitocidal treatment with primaquine.

*Correspondence: michael.ramharter@medizin.uni-tuebingen.de

${ }^{2}$ Institut für Tropenmedizin, Universität Tübingen, Tübingen, Germany

Full list of author information is available at the end of the article 


\section{Case presentation}

A 16-year-old male patient presented with a 5-day history of recurrent fever attacks up to $39.5{ }^{\circ} \mathrm{C}$ and with night sweats and arthralgia to the outpatient department (OPD) of the infectious diseases ward of the General Hospital of Vienna. Laboratory examination indicated a moderately increased CRP $(1.57 \mathrm{mg} / \mathrm{dL})$ with a normal white blood count, thrombocytopaenia of $105 \mathrm{~g} / \mathrm{L}$, a moderately raised total bilirubin of $2.33 \mathrm{mg} / \mathrm{dL}$ in addition to moderately increased LDH of 277 U/L. Differential blood count showed monocytosis and atypical lymphocytes. A rapid diagnostic influenza test $\left(\mathrm{Xpert}^{\circledR}\right.$ Flu, Cepheid) was negative for Influenza A and Influenza $\mathrm{B}$, as well as ELISAs for CMV and EBV. An aerobic blood culture was positive for Staphylococcus hominis after $20.4 \mathrm{~h}$. This was not confirmed by other simultaneously drawn blood culture sets and was thus regarded as contamination. Physical examination was normal apart from an enlarged sub-angular lymph node on the right side. The anamnesis revealed that the patient had returned from a trip of $1 \frac{1 / 2}{2}$ months in duration, to Uganda, Papua New Guinea and Singapore, 3 months before the onset of symptoms. During this stay and until 3 weeks after returning home, he took continuous malaria prophylaxis consisting of mefloquine $\left(\right.$ Lariam $\left.^{\circledR}\right)$ once per week. He did not report any associated complaints. Eight months before, he had stayed at the Philippines for 10 days.

Thick and thin blood smears were performed and Plasmodium malariae was diagnosed microscopically. A routine therapy with six adult doses of Riamet ${ }^{\circledR}$ (artemether-lumefantrine) was initiated according to the manufacturer's recommendations and following WHO treatment guidelines. On the first day of treatment body temperature increased to a maximum of $39.8{ }^{\circ} \mathrm{C}$, but the general health status improved subsequently. A thick blood smear on the last day of treatment was negative and the patient was discharged in good condition. A follow-up examination was planned for 1 week after admission to which the patient, however, did not present.

One month later, the patient returned to the outpatient department with reported fever. He had not travelled abroad since the initial malaria diagnosis. A thick blood smear showed a recurrence of parasites with a very low parasitaemia. The patient was retreated with Riamet ${ }^{\circledR}$ and samples from the first and second fever episode were sent for species specific PCR diagnosis [3]. PCR from EDTA blood detected a $P$. ovale wallikeri mono-infection at both time points. Further analyses were initiated with the aim to identify whether the second attack was a relapse of the same parasite isolate or a prolonged latency of another P. ovale wallikeri parasite obtained during the preceding trips.
Molecular analysis of several gene loci was conducted to evaluate both isolates. Initially, a fragment of the nuclear $18 S$ rRNA gene was analysed to identify Plasmodium spp. (Primers rOVA1WC/rOVA2WC) [4]. The positive isolates were further analysed for discrimination between $P$. ovale curtisi (rOVA1/rOVA2) [5] and $P$. ovale wallikeri (rOVA1v/rOVA2v) [3]. To examine if the isolates were identical genotypes the nuclear porbp 2 and potra genes were analysed.

Examined sequences of the SSU rRNA, porbp $2[6,7]$ and potra [8] genes revealed homology of the two isolates. The sequences can be accessed in GenBank with the numbers (MG251661-P. ovale wallikeri isolate 17T1554/17T186R. porbp2, MG255222-MG255223P. ovale wallikeri isolate 17T1554/17T186R SSU rRNA gene, partial sequence).

Accordingly, the patient's glucose-6-phosphate dehydrogenase (G6PD) status was tested and showed normal enzyme function so that a 14 days course of primaquine was initiated [9]. During the following 7 months, the patient did not experience further episodes of disease.

\section{Discussion and conclusions}

Detection of Plasmodium by microscopy of blood smears is still the gold standard for malaria diagnosis and provides a fast and valid diagnostic tool when performed by experienced slide readers. Since the introduction of species-specific diagnosis using PCR it has, however, become more and more evident that a considerable number of microscopically retrieved results are inaccurate, especially concerning species distinction in non-falciparum and mixed Plasmodium infections [10-12]. The here described case underlines the usefulness of diagnostic confirmation by PCR and its possible clinical importance.

This case adds valuable information to the scarce evidence available in the literature on the relapse hypothesis for $P$. ovale malaria. To current knowledge, no other case with subsequent molecular analysis of primary and recurring infection has been reported from a nonendemic area $[2,13]$. Here, a re-infection can be excluded as the patient remained in a non-malaria endemic country after treatment of the initial malaria episode. Also, the possibility of prolonged latency of a different $P$. ovale parasite originally acquired at the same time causing the second episode is negligible as the obtained sequence data strongly suggest the presence of the identical malaria parasite during the initial and the recurring episodes. Here, sample amount was not sufficient but in upcoming studies whole genome sequencing is recommended to prove identical genotypes. More difficult is a distinction between recrudescence and relapse. However, the bloodstage medication was taken under observation and there are no known specific drug resistance mechanisms for 
P. ovale spp. against artemether or lumefantrine, thus a recrudescence seems very unlikely.

Anti-hypnozoite treatment with 8-aminoquinolines was introduced based on the observation that quinine therapy was more efficacious in combination with the 8-aminoquinoline pamaquine for the treatment of relapsing $P$. vivax infections than as monotherapy. Based on this, 8-aminoquinolines were further developed, but their effectiveness against relapsing $P$. ovale infections was merely presumed [14]. Models for testing hypnozoitocidal drugs for any species are not easy to develop which complicates research and development of new compounds that are also suitable for broad use. Recent experiments in humanized mice suggest the formation of P. ovale dormancies in human liver cells, if only for a limited time, and raise hope that more light will be shed on the relapse phenomenon $[15,16]$.

In 2015, Robinson et al. conducted a randomized double-blind placebo-controlled trial comparing blood stage drugs plus primaquine to blood stage drugs plus placebo in Papua New Guinean children [17]. The included patients were allocated to the respective treatment groups and followed for 32 weeks. Within this period, the qPCR-corrected time to the first clinical malaria episode was studied. The risk of having at least one PCR detectable $P$. ovale infection within the 8 months of follow up was significantly lower in the group that received primaquine. The same was true for P. vivax. For Plasmodium falciparum or $P$. malariae, however, no significant association of this kind could be observed. These results support the hypothesis of a quiescent parasite stage that is affected by primaquine. Yet it is to note that this was a limited sample size and no analyses were made regarding whether the observed episodes were following a previous $P$. ovale infection or not.

Interestingly, recent studies doubt the exclusive connection between liver dormancies and tertian malaria and suggest other havens of dormancies and a relapse potential of all human infective Plasmodium spp., respectively $[1,18,19]$. Indeed, when having a closer look at the history of publications on dormancies derived from non-human Plasmodium spp., dormant stages were also reported in the epidermis, brain, spleen, kidneys and lungs [20,21]. Further case reports or small retrospective analyses of possible relapse cases can be found in the scientific literature, however, without supporting molecular analyses [22, 23].

This case report provides an important piece in the puzzle to substantiate the relapsing properties of $P$. ovale. Still, more evaluations of this kind are needed and the causal relationship between relapse and liver dormancies remains to be further explored.

\section{Abbreviations}

ACT: artemisinin based combination therapy; CMV: cytomegalovirus; EBV: Epstein-Barr virus; G6PD: glucose-6-phosphate dehydrogenase; OPD: outpatient department; PCR: polymerase chain reaction; porbp2: Plasmodium ovale reticulocyte binding protein 2; potra: Plasmodium ovale tryptophan-rich antigen; spp.: species; SSU: rRNA small subunit ribosomal ribonucleic acid; WHO: World Health Organization.

\section{Authors' contributions}

LV, MG and HL coordinated sampling and drafted the manuscript. JW and HA performed primary molecular analyses and helped drafting the manuscript. HPF performed further PCR and molecular testing and drafted the manuscript. MR revised the manuscript and supervised the group. All authors read and approved the final manuscript.

\section{Author details}

${ }^{1}$ Division of Infectious Diseases and Tropical Medicine, Department of Medicine I, Medical University of Vienna, Vienna, Austria. ${ }^{2}$ Institut für Tropenmedizin, Universität Tübingen, Tübingen, Germany. ${ }^{3}$ Institute for Specific Prophylaxis and Tropical Medicine, Medical University of Vienna, Vienna, Austria. ${ }^{4}$ Department of Pathobiology, Institute of Parasitology, University of Veterinary Medicine Vienna, Vienna, Austria. ${ }^{5}$ Bernhard Nocht Hospital for Tropical Diseases, Bernhard Nocht Institute for Tropical Medicine and University Medical Center Hamburg-Eppendorf, Hamburg, Germany.

\section{Acknowledgements}

We thank all colleagues helping and Renate Schneider from the Institute for Specific Prophylaxis and Tropical Medicine for excellent technical assistance.

\section{Competing interests}

The authors declare that they have no competing interests.

\section{Availability of data and materials}

The datasets will be made available upon reasonable request from the corresponding author. Gene sequences can be found on GenBank.

\section{Consent for publication}

According to the regulations of the Medical University of Vienna and the editorial policies, no consent for publication was required.

Ethics approval and consent to participate

Not applicable.

Funding

No funding.

\section{Publisher's Note}

Springer Nature remains neutral with regard to jurisdictional claims in published maps and institutional affiliations.

Received: 23 October 2017 Accepted: 7 February 2018

Published online: 09 February 2018

\section{References}

1. Richter J, Franken G, Mehlhorn H, Labisch A, Häussinger D. What is the evidence for the existence of Plasmodium ovale hypnozoites? Parasitol Res. 2010;107:1285-90.

2. Groger M, Fischer HS, Veletzky L, Lalremruata A, Ramharter M. A systematic review of the clinical presentation, treatment and relapse characteristics of human Plasmodium ovale malaria. Malar J. 2017;16:112.

3. Calderaro A, Piccolo G, Perandin F, Gorrini C, Peruzzi S, Zuelli C, et al. Genetic polymorphisms influence Plasmodium ovale PCR detection accuracy. J Clin Microbiol. 2007;45:1624-7.

4. Fuehrer H-P, Stadler M-T, Buczolich K, Bloeschl I, Noedl H. Two techniques for simultaneous identification of Plasmodium ovale curtisi and Plasmodium ovale wallikeri by use of the small-subunit rRNA gene. J Clin Microbiol. 2012;50:4100-2. 
5. Snounou G, Viriyakosol S, Zhu XP, Jarra W, Pinheiro L, do Rosario VE, et al. High sensitivity of detection of human malaria parasites by the use of nested polymerase chain reaction. Mol Biochem Parasitol. 1993;61:315-20.

6. Sutherland CJ, Tanomsing N, Nolder D, Oguike M, Jennison C, Pukrittayakamee $\mathrm{S}$, et al. Two nonrecombining sympatric forms of the human malaria parasite Plasmodium ovale occur globally. J Infect Dis. 2010;201:1544-50.

7. Oguike MC, Betson M, Burke M, Nolder D, Stothard JR, Kleinschmidt I, et al. Plasmodium ovale curtisi and Plasmodium ovale wallikeri circulate simultaneously in African communities. Int J Parasitol. 2011:41:677-83.

8. Tanomsing N, Imwong M, Sutherland CJ, Dolecek C, Hien TT, Nosten F, et al. Genetic marker suitable for identification and genotyping of Plasmodium ovale curtisi and Plasmodium ovale wallikeri. J Clin Microbiol. 2013;51:4213-6.

9. WHO. Guidelines for the treatment of malaria. 3rd ed. Geneva: World Health Organization; http://www.who.int/malaria/publications/ atoz/9789241549127/en/. Accessed 11 Mar 2017.

10. Alemu A, Fuehrer H-P, Getnet G, Kassu A, Getie S, Noedl H. Comparison of Giemsa microscopy with nested PCR for the diagnosis of malaria in North Gondar, north-west Ethiopia. Malar J. 2014;13:174.

11. Chavatte J-M, Tan SBH, Snounou G, Lin RTPV. Molecular characterization of misidentified Plasmodium ovale imported cases in Singapore. Malar J. 2015;14:454.

12. Cao Y, Wang W, Liu Y, Cotter C, Zhou H, Zhu G, et al. The increasing importance of Plasmodium ovale and Plasmodium malariae in a malaria elimination setting: an observational study of imported cases in Jiangsu Province, China, 2011-2014. Malar J. 2016;15:459.

13. Starzengruber P, Fuehrer H-P, Swoboda P, Khan WA, Yunus EB, Hossain SM, et al. The first case of Plasmodium ovale malaria from Bangladesh. BMJ Case Rep. 2010;2010:bcr0320102865.
14. Wernsdorfer WH, McGregor I. Malaria: principles and practice of malariology. London: Churchill Livingstone; 1988.

15. Soulard V, Bosson-Vanga H, Lorthiois A, Roucher C, Franetich J-F, Zanghi $\mathrm{G}$, et al. Plasmodium falciparum full life cycle and Plasmodium ovale liver stages in humanized mice. Nat Commun. 2015;6:7690.

16. Mikolajczak SA, Vaughan AM, Kangwanrangsan N, Roobsoong W, Fishbaugher M, Yimamnuaychok N, et al. Plasmodium vivax liver stage development and hypnozoite persistence in human liver-chimeric mice. Cell Host Microbe. 2015;17:526-35.

17. Robinson LJ, Wampfler R, Betuela I, Karl S, White MT, Li Wai Suen CSN, et al. Strategies for understanding and reducing the Plasmodium vivax and Plasmodium ovale hypnozoite reservoir in Papua New Guinean children: a randomised placebo-controlled trial and mathematical model. PLoS Med. 2015;12:e1001891.

18. Richter J, Franken G, Holtfreter MC, Walter S, Labisch A, Mehlhorn H. Clinical implications of a gradual dormancy concept in malaria. Parasitol Res. 2016;115:2139-48.

19. Markus MB. Do hypnozoites cause relapse in malaria? Trends Parasitol. 2015;31:239-45.

20. James SP, Tate P. Exo-erythrocytic schizogony in Plasmodium gallinaceum Brumpt, 1935. Parasitology. 1938;30:128.

21. Mayne B. Protracted incubation in malarial fever: report of a case and a review of the literature. Public Health Rep. 1937;52:1599.

22. Bottieau E, Van Gompel A, Peetermans WE. Failure of primaquine therapy for the treatment of Plasmodium ovale malaria. Clin Infect Dis. 2005;41:1544-5.

23. Nathwani D, Currie PF, Smith CC, Khaund R. Recurrent Plasmodium ovale infection from Papua New Guinea_chloroquine resistance or inadequate primaquine therapy? J Infect. 1991;23:343-4.

\section{Submit your next manuscript to BioMed Central and we will help you at every step:}

- We accept pre-submission inquiries

- Our selector tool helps you to find the most relevant journal

- We provide round the clock customer support

- Convenient online submission

- Thorough peer review

- Inclusion in PubMed and all major indexing services

- Maximum visibility for your research

Submit your manuscript at www.biomedcentral.com/submit
O Biomed Central 